\title{
Prologue
}

\section{DIVERSE STRUCTURES, SAME SCIENCE}

Donat G. Wentzel

University of Maryland, College Park, Maryland 20742, U.S.A.

This is truly an international gathering, as befits the IAU. We have a wide range of educational backgrounds. Most of us hope to adapt each others' ideas to suit our own needs. That adaption will be much easier if we appreciate each others' individual circumstances, and especially if we know something about each others' different educational systems. To ease the exchange of information, I shall outline two very different educational schemes. I shall call them the "traditional" and the "U.S." system. I suspect that about half of us will identify more closely with the traditional system, and half with the U.S. system.

The table outlines the main features of the two systems according to age, because children and students think alike at a given age no matter where they live. The differences between the two educational systems arise mainly from different social goals.

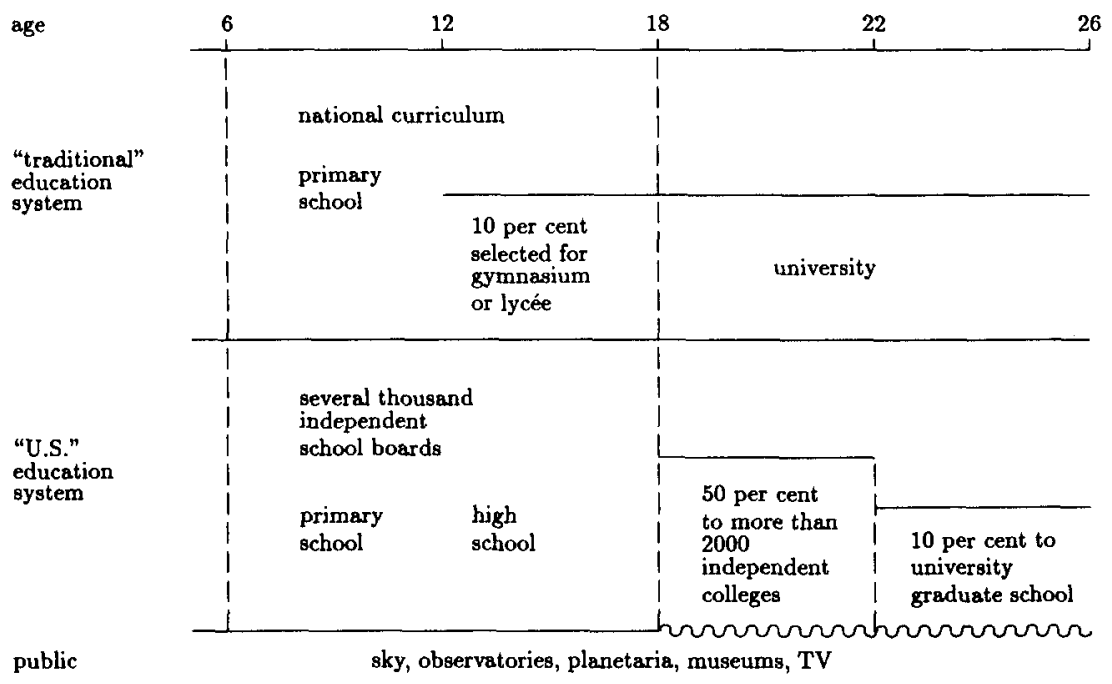

The two systems are fairly similar in the primary grades, until age 12 . Then the traditional system identifies several pathways for further education. The children are sent to separate schools according to their general ability in academic subjects. 
A rather small fraction is selected for university studies. This fraction has grown in the last two decades. Nevertheless, university study still implies a privilege. It also implies a duty for rigorous study, starting already at age 12. If children and older students study astronomy, they consider astronomy as a rigorous physical science.

The U.S. system has a very much broader goal. For social reasons, the U.S. system seeks to provide the same education for almost all through high school, usually age 18 . The brightest children may take more advanced subjects, but they usually remain in a school that must accommodate the needs of all children.

At age 18, about half the U.S. population continues into college. Therefore, a college education serves a very different group of people than does a university education in the traditional system. Studies in most U.S. colleges are much less rigorous than in traditional universities. In particular, college astronomy courses for non-astronomy, non-physics majors are rather descriptive and contain little mathematics.

The U.S. college system has emphasized those aspects of the physical sciences that can be made popularly attractive. The system attempts to treat science as a part of culture, much as is literature, history, and painting. Astronomy is perhaps the physical science most suitable for such a cultural treatment. There is a substantial overlap with the goals of public education in astronomy. I have shown that overlap by the wiggly line in the table between college education and public education.

The "popularized" college astronomy courses have a very broad impact: probably one out of eight young adults in the United States has had an astronomy course, and they tend to remember that course with some pleasure. Many politicians have had a smattering of astronomy even if they always dreaded math and physics. Many of these politicians have learned to appreciate the goals of the physical sciences, and they can influence policy all the way from local governments to the federal government. They may willingly vote funds to support science in principle because of their astronomy experience. Unfortunately, they may not appreciate the rigor needed to carry out that science. They do not appreciate that science requires support over many years. Consequently, the support of science in the U.S. changes from year to year, depending on the political winds. This is very obvious in the U.S. space program, where some major projects have been turned on, off, and then on again. But other parts of U.S. science are also insecure. For instance, the budgets of many state universities tend to rise in an election year, and then languish the next year. The support of science at those universities changes similarly.

The U.S. educational system has probably become too popularized. There is now a widespread complaint that U.S. college graduates are scientifically illiterate. A video program has been made about students who are just finishing college at the prestigious Harvard University. They are asked to explain the seasons. They explain with much conviction that summer occurs because the Earth is then closer to the sun. (see paper by P. Sadler.) More rigorous study is again becoming fashionable. But the system of providing nearly the same education for everyone will remain. That goal is probably the ultimate limitation of the U.S. educational system. 
There is another important difference between the two systems: the traditional educational systems tend to be structured on a national basis. The important examinations are nationwide and certificates are nationwide. Some countries represented here have very advanced standards in astronomy; some countries are just beginning with astronomy. But in nearly all countries there is an effort to establish a national program.

In the U.S., a national program is avoided for historical reasons. Education is local. The class content for primary and high schools is decided by several thousand independent school boards. The members of most of these school boards are elected. They must respond to the wishes of all the local voters. If the local voters see no need for the physical sciences, then the schools offer hardly any science at all. If the local voters are well educated, they may vote for a superb school system. Some school districts have established schools that specialize in the teaching of science. There are a few high schools in the United States (such as the Bronx High School of Science in New York City) that are as rigorous and difficult as any German Gymnasium or a Lycée in France, etc.

The course content in U.S. colleges is decided by several thousand independent colleges and several hundred universities. Most of them are publicly supported, typically by the county or by the state government. These colleges must respond to the needs of the local community, just as the high schools do. Some colleges and universities are private and obtain much of their income from investments. They can set more lofty educational goals, but they may have to limit those goals when the value of their investments declines.

The independence of all these schools and colleges makes the U.S. system rather complex. One must learn to rank the colleges and even some high schools. Where the German student simply says that he made the Abitur, the U.S. student says that he graduated from Williams College, or he received a "bachelors degree" from the University of Chicago, or he went to the Bronx High School of Science, and so on.

My goal in this outline is to stress the tremendous diversity of our needs at this colloquium because we come from many countries and many kinds of institutions. When we exchange experiences, we should always identify our background and the kind of students we teach.

Fortunately, we do have a common science. We have the same media to reach the public. The same questions on astronomy education are probably asked in every country represented at this colloquium.

One common question is: Just how much astronomy can school children really understand? For example, at what age can they understand the phases of the moon? That explanation requires children to imagine the world simultaneously from the different perspectives of the Earth and the sun. Apparently, some minimum age is needed before children can imagine even one perspective that is beyond their immediate experience. In teaching lunar phases, we ask children to imagine two perspectives! We astronomers tend to ask more of children than we should expect. We must ask more often when our subject can be introduced in a useful fashion. We 
should also consider whether tools like a planetarium can make the learning easier.

Problems with logical ability are not limited to the primary grades. In the U.S., at least, we also run into limited logical ability at the university level. I shall cite one obvious example. It is easy for students to understand that the parallax of a star is smaller the further the star. But what would happen if we could also double the baseline? That extra choice already confuses many college students. And what could we measure if we also improved the angular resolution of the telescope? That question involves three variables. So many variables tend to boggle the student's mind. The student cannot sort out the logical steps. Yet we astronomers use such complex arguments all the time. We discuss the H-R diagram in that way, and the age of the universe. When we exceed the students' logical ability, we stop educating and merely cause frustration. I hope we learn from each other at this colloquium how to teach astronomy at a level that is effective for the student.

Another common question is: What aspect of astronomy should we teach if only part of a course is available for astronomy? Traditionally, the answer has often been: celestial mechanics. There is a practical reason for this answer. Celestial mechanics is easily integrated into mathematics and physics courses. But it is a rather abstract subject, and it is logically quite difficult. For other topics, during the last two decades, hands-on experiments have been devised that many students can carry out themselves. Even computers can now be used for informative experiments. Such experiments provide a new avenue for introducing astronomy into many different courses of instruction. They permit students to discover the world by themselves. Such learning is vastly more effective than rote learning from books. I hope we shall hear of many interesting hands-on and computer experiments during this colloquium.

Perhaps the greatest challenge to astronomy teaching lies not in the detailed choices of topics or exercises, but in presenting astronomy as an intellectual stimulation to the students. Astronomy can lead students to create for themselves a view of the world, using the perspectives that have been forged by astronomers over the last few centuries. I think students must be stimulated to form some world view. I hope we learn at this colloquium how to stimulate the students more effectively.

Finally, at the university level, we must teach future astronomers and astronomy teachers. In the United States, education beyond college is called "graduate school". At this level, the traditional and U.S. systems are quite similar. Unfortunately, rather few U.S. students choose rigorous studies in physics during college. Therefore, only a few can later study physics or astronomy in graduate school. About half the U.S. graduate students in physics and astronomy are now from outside the U.S., mostly from Asia. Both American and European universities have many students from developing countries. One subject for discussion at this colloquium should be the job opportunities for astronomers returning to their own countries, and the training that is really appropriate for astronomers returning to astronomically developing countries.

The IAU has created the Commission 46 on the Teaching of Astronomy. It has the goal of enhancing opportunities for astronomy education internationally. The 
major Commission projects have been:

- the International Schools for Young Astronomers (ISYA), of which there have been sixteen,

- the Visiting Lecturers Program (VLP), so far operating in Peru and Paraguay, and awaiting a start in Nigeria,

- the Commission Newsletter, of which there have been two dozen,

- the list of Astronomy Educational Materials and the National Reports on Astronomy Teaching, prepared for seven IAU General Assemblies,

- meetings with local teachers on the day before IAU General Assemblies,

- and this colloquium.

The ISYA and VLP support the professional training of astronomers. The Newsletter has carried several articles on the astronomy training of teachers, but so far the IAU has no formal arrangement supporting teacher training.

I hope that this colloquium leads to additional concrete ways in which the IAU and Commission 46 can aid astronomy education. We have good reason to teach astronomy: it is an exciting subject that spurs the imagination. We should capitalize on that opportunity.

\section{Discussion}

J.-C. Pecker: Your fine diagram puts a vertical boundary line at the age of 26. But we should, I believe, consider also the importance of adult-oriented teaching of astronomy. This concerns the astronomy teachers - who have to learn all their life - as well as the "general" public (including politicians!); TV broadcasts, for example, may be a positive asset (although, in general, they often tend to destroy the good effects of education given to the people when they were younger!).

J.C. LoPresto: Public education and professional science education are difficult to accomplish simultaneously. Colleges are not the only format for public education. What is your opinions?

D. Wentzel: Definitely museums, TV, etc., are a major branch of science education for astronomy. That is why they have their own column in my table. The wiggly line between U.S. colleges and public education merely indicates one of the few connections between the systems. 


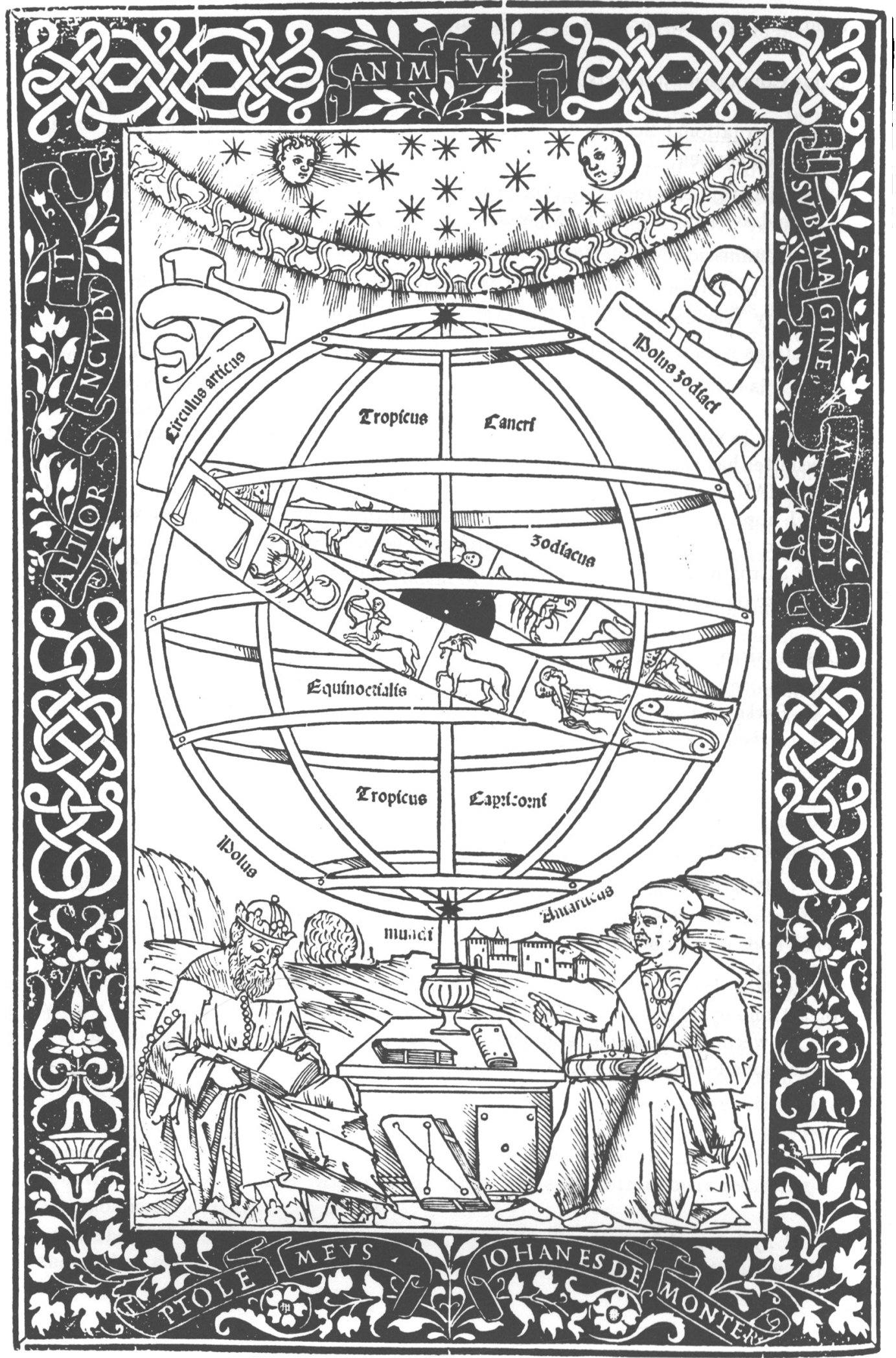

Ptolemy and Regiomontanus with Armillary Sphere, artist unknown; Frontispiece of Epytoma in Almagestum Ptolomei, by Johannes Regiomontanus. Chapin Library of Rare Books, Williams College. Further information on page 435. 